\title{
Serguei Dovlátov no contexto da terceira onda de emigração russa
}

\author{
Yulia Mikaelyan ${ }^{1}$
}

\begin{abstract}
The historical and political events of the 20th century led to four waves of emigration of the Russian population abroad. This article aims to give a brief review of the historical and cultural context of this emigration, with emphasis on the Third Wave, and analyse the place of the writer and journalist Sergei Dovlatov in the literary colony of New York in the 80s and his role in the Russian literary tradition.
\end{abstract}

Keywords: Sergei Dovlatov; Russian emigration; the Third Wave; Russian classic literature.

Resumo: Os acontecimentos históricos e políticos ao longo do século XX levaram a quatro ondas de emigração da população russa para o exterior. Este artigo tem como propósito fazer uma breve resenha do contexto histórico e cultural das ondas de emigração russa, dando ênfase à terceira onda de emigração, e analisar o lugar do escritor e jornalista Serguei Dovlátov na colônia literária nova-iorquina dos anos 80 e seu papel na tradição literária russa.

Palavras-chave: Serguei Dovlátov; emigração russa; terceira onda de emigração; literatura clássica russa.

\section{As emigrações russas ao longo do século XX: contexto histórico, político e cultural}

Durante o século $\mathrm{XX}$, os acontecimentos históricos e políticos levaram a várias ondas de emigração da população da Rússia (e, depois, da União Soviética) para o exterior. Os historiadores distinguem quatro ondas de emigração ao longo do século passado: a primeira onda, nos anos 20; a segunda onda, nos anos 40; a terceira onda, nos anos 70-80; e a quarta onda, nos anos 90.

A primeira onda de emigração, também conhecida como "a emigração branca" (pois a maioria dos emigrados simpatizava com o antigo regime e com o exército branco que o representava na guerra civil, chamado assim em oposição ao exército "vermelho", pró-revolução), era relacionada com a revolução de outubro e a guerra civil que a seguiu. Nessa época, saíram do país principalmente descendentes da nobreza russa e intelectuais que não aceitaram o regime comunista. Muitos artistas e pensadores foram obrigados a abandonar o país, entre eles escritores como V. Nabókov, I. Búnin, A. Kuprin, D. Merejkóvski, Z. Guíppius, entre outros.

A segunda onda, conhecida também como "a emigração pós-guerra", foi constituída principalmente pelas pessoas que foram deslocadas à força durante a Segunda

\footnotetext{
${ }^{1}$ Doutoranda do programa de Literatura e Cultura Russa do Departamento de Letras Orientais da Faculdade de Filosofia, Letras e Ciências Humanas da Universidade de São Paulo (FFLCH/USP). E-mail: ymikaelyan@usp.br.
} 
Guerra Mundial e acabaram não voltando para sua terra natal (displaced persons, ou abreviado como DP, em inglês) e pelos habitantes das repúblicas do mar Báltico que se recusavam a reconhecer o poder da União Soviética. Foi durante a segunda onda de emigração que se estabeleceram colônias russas nos Estados Unidos, principalmente em Nova York e São Francisco, colônias que geraram ali sua própria imprensa: o jornal Novoe Russkoe Slovo e a revista Nóvyi Jurnal. Entre os escritores representantes dessa onda de emigração podemos destacar Iúri Ivask, Dmítri Klenóvski, Ivan Eláguin. Mas, em geral, a segunda onda gerou poucos nomes de referência no âmbito da literatura e das artes.

A terceira onda, conhecida como a emigração dos dissidentes e às vezes também chamada de "emigração judia”, começou numa época de estagnação na União Soviética, quando, no começo dos anos 70, foram liberados para sair e morar permantentemente no exterior os judeus soviéticos e também os que não concordavam com o regime e eram perseguidos por suas opiniões políticas, os dissidentes. Durante aproximadamente 20 anos (a terceira onda de emigração durou até o final dos anos 80), saíram ou foram expulsos do país muitos intelectuais e artistas (a assim chamada "intelliguêntsia criativa", tvórtcheskaia intelliguêntsia, em russo), entre eles a grande maioria dos escritores contemporâneos mais significativos que não aceitavam o regime estabelecido no país. $\mathrm{O}$ eslavista Arnold McMillin chamou essa onda de emigração de um dos acontecimentos mais dramáticos na cultura europeia contemporânea, "trágico e ao mesmo tempo promissor" (McMillin, 1989, p. 406). Nesse período, emigraram V. Aksiónov, J. Brodsky, A. Soljenítsyn, S. Dovlátov, A. Siniávski, E. Limónov, entre outros. Os destinos dos emigrados da União Soviética foram diferentes: assim, muitos judeus soviéticos foram a Israel; uma parte dos emigrados se instalou em países europeus (como Alemanha e França) e um grande número foi para os Estados Unidos.

A quarta onda (dos anos 90) começou com a queda da cortina de ferro, levando para o exterior as minorias étnicas russas (principalmente judeus e alemães). Devido ao pouco tempo que se passou depois dessa última onda de emigração, ainda não há muitos estudos sobre seus representantes culturais e literários.

Como uma maior presença de intelectuais está relacionada com a primeira e com a terceira ondas de emigração, elas serão o foco de nossa atenção neste artigo, principalmente a terceira onda de emigração e um dos seus maiores representantes, o escritor Serguei Dovlátov (Ufá, 1941 - Nova York, 1990).

Embora todas as ondas formassem uma continuidade, em razão da pertinência a uma mesma cultura e à autodefinição por meio da língua russa, pensando-se no contexto 
histórico-cultural, é importante destacar alguns traços característicos que diferenciam as ondas entre si. Assim, além de carecer de um desenvolvimento intelectual tão grande, a segunda onda de emigração, em comparação com a primeira, já não possuía laços tão fortes nem com a cultura ocidental (pois a maioria dos emigrados nobres era bilíngue e tinha formação europeia), nem com a cultura do Século de Prata (pois eram já moradores de outro país: não do Império Russo, mas da União Soviética).

E a maior parte dos intelectuais representantes da terceira onda de emigração tinha uma postura diferente daquela das primeiras gerações de emigrados quanto ao seu futuro. Para a maioria dos emigrados dos anos 20, a emigração era uma condição temporária, pois poucos acreditavam que o novo regime soviético durasse muito tempo. Portanto, os primeiros emigrados guardavam os costumes e a própria língua com um cuidado especial, pensando que voltariam à terra natal após a queda do poder soviético. Além disso, como a emigração consistia principalmente de russos de origem nobre, muitos deles intelectuais, eles se sentiam portadores e protetores "daquela Rússia” que os bolcheviques ousaram arruinar. Como menciona David Bethea, as duas primeiras ondas de emigração caracterizavam-se por manter "um olhar nostálgico para o passado", sem muita capacidade de olhar para o futuro da emigração (Bethea, 1987, p. 155).

Já a postura dos dissidentes recém-chegados ao Ocidente nos anos 70 foi bastante diversa: expulsos pelo regime e muitos perseguidos por suas opiniões políticas ou devido ao antissemitismo, que na época era apoiado pelo próprio Estado (para um judeu, era muito mais difícil entrar numa universidade de alto prestígio e praticamente impossível obter um alto cargo de funcionário público), a maioria dos emigrados tinha uma visão clara de que sua emigração seria definitiva e, diferentemente dos representantes da "emigração branca", não objetivava guardar com tanto empenho as memórias da vida e da cultura da terra natal, mas, ao contrário, deveria adaptar-se ao novo país e às novas condições de vida.

O nome de Aleksandr Soljenítsyn, no contexto da terceira onda, merece uma atenção especial, pois o próprio escritor e filósofo sempre se manteve muito próximo à tradição e à cultura russa e nunca saiu desse contexto, tampouco se considerou um emigrado, mas um exilado político, afirmando ter sido forçado a deixar o país e voltando à Rússia assim que se modificou o regime político. Como menciona David Bethea, Soljenítsyn "poderia pertencer à terceira onda fisicamente, mas não espiritualmente, suas origens remontam à outra Rússia, à Rússia de Matriona (a personagem principal do conto do escritor Matriónin Dvor) e à de Tolstói e Dostoiévski” (ibid., p. 159). 


\section{O lugar de S. Dovlátov na Nova York literária russa}

Como durante a terceira onda de emigração muitos escritores vão para os Estados Unidos, ali se forma uma forte colônia literária russa, constituída por vários grandes nomes, entre eles, J. Brodsky, S. Dovlátov, V. Aksiónov, Y. Alechkóvski. O centro dessa colônia foi a cidade de Nova York, que já recebera russos de outras ondas de emigração e, em meados dos anos 70, tinha vida literária própria no círculo dos emigrados russos. Essa vida literária, com certeza, foi enriquecida com a chegada de uma nova leva de escritores, jornalistas e críticos literários que, finalmente livres para exercer seu trabalho sem censura e perseguição do poder, começaram a contribuir com seus escritos. Assim, nos anos 70-80, nos Estados Unidos, surgiram vários jornais e revistas em língua russa para a comunidade nova-iorquina (como Síntaksis, Kovtcheg, Ekho, Vriémia i My, Dvádtsat Dva, Nóvyi Amerikánets, entre outras) e outros já existentes receberam nova vida e novos temas com os autores recém-chegados.

A perseguição por parte do governo às opiniões políticas e a exclusão da profissão (os escritores dissidentes não tinham chance de entrar na literatura oficial) foram os motivos principais da emigração de muitos escritores e intelectuais. Também foi assim a trajetória da emigração do escritor e jornalista Serguei Dovlátov.

Participante do círculo literário de Leningrado, Dovlátov teve sua publicação proibida na União Soviética por opiniões que não coincidiam com a ideologia oficial e chegou a ser perseguido pela polícia logo antes de emigrar, em 1978. No entanto, o escritor nunca tocou em temas políticos ou ideológicos em sua obra e ele mesmo não se considerava dissidente. Descrevia assim sua posição na União Soviética: "Na União Soviética eu não era dissidente. (A bebedeira não conta.) Eu apenas escrevia contos alheios à ideologia. Então tive que ir embora. Eu me tornei dissidente na América"2 (Dovlátov, 1983).

Como a maioria dos representantes da literatura soviética não oficial (paralela à literatura oficial, apoiada pelo governo e que expressava sua ideologia), Dovlátov distribuía sua obra por meio de samizdat (manuscritos copiados à máquina pelos próprios autores e leitores e que circulavam clandestinamente) e de tamizdat (livros e revistas publicados em russo no exterior), portanto, acessível a um círculo de leitores muito limitado. Já na emigração, Dovlátov falava em palestras e entrevistas sobre as razões de sua saída da União Soviética, marcando como razão principal para emigrar, além das perseguições, a impossibilidade de exercer a profissão de escritor e de ter acesso ao público. Na entrevista à revista nova-iorquina da comunidade russa Slovo-Word, ele

\footnotetext{
${ }^{2}$ Deste ponto em diante, todas as traduções do russo apresentadas são elaboradas pela autora deste artigo.
} 
explica assim seus motivos para a emigração: "Eu fui embora para ser escritor, e me tornei escritor ao fazer uma escolha não muito difícil entre a prisão e Nova York" (Dovlátov, 1991).

Ao chegar aos Estados Unidos, Dovlátov começou a participar ativamente da vida literária de Nova York. Além do trabalho como escritor (no total, durante os 12 anos de vida do escritor na emigração, nos Estados Unidos e na Europa foram publicados 12 livros seus), Dovlátov exerceu a função de jornalista (que era sua profisssão "oficial" na União Soviética). Assim, durante a vida na emigração, Dovlátov colaborou com a famosa rádio Liberty (o público soviético o conhecia, além dos samizdat, por seu programa " $\mathrm{O}$ escritor ao microfone", Pissátel u mikrofona) e, de 1980 a 1982, foi redator-chefe do jornal semanal Nóvyi Amerikánets, um dos periódicos de maior referência na época entre a colônia russa nos Estados Unidos.

Tanto na União Soviética quanto nos Estados Unidos, Serguei Dovlátov trabalhou como jornalista, e isto se reflete em sua obra: os gêneros preferidos do autor são crônicas e contos curtos, e tem como marcas de estilo o laconismo das frases, o uso de palavras estilisticamente neutras e o pseudodocumentalismo.

Mas, para o próprio Dovlátov, o único trabalho sério sempre fora a literatura e, na profissão de jornalista, ele via apenas um modo de sustentar a família, chamando-a de "quebra-galhos" (khaltura, em russo) (Sukhikh, 2012, p. 31). O sucesso da obra do escritor pelo mundo provou, posteriormente, o quanto seu talento era maior do que a esfera apenas jornalística. A esse respeito, o crítico americano de origem letônia Aleksandr Guenis brinca, caracterizando a relação de Serguei Dovlátov com o jornal Nóvyi Amerikánets e com a profissão de jornalista, em geral, da seguinte maneira: “Poderíamos esgotar o tema 'Dovlátov e o jornal' em duas palavras, dizendo que ele não cabia ali” (Guenis, 2006, p. 13). O crítico faz referência não só ao tamanho do talento do escritor, mas também, sarcasticamente, a seu tamanho físico, pois Dovlátov tinha quase 2 metros de altura.

No entanto, já na vida do escritor em emigração, sua obra foi reconhecida não apenas pelo público russo da colônia, mas também pelos leitores americanos (além de Brodsky e Soljenítsyn, Dovlátov foi o terceiro escritor russo no exterior que mereceu o maior número de artigos críticos na imprensa estrangeira, quase todos elogiosos). Como exemplo disso, há o fato de que as traduções de contos de Serguei Dovlátov foram publicadas nas revistas Partisan Review e New Yorker e sua obra foi valorizada pelo clássico vivo americano Kurt Vonnegut, com quem ele mantinha correspondência nos $\operatorname{anos} 80$. 
O próprio Dovlátov sempre foi muito grato a seu amigo ainda da época de Leningrado, Joseph Brodsky, que, já sendo famoso nos Estados Unidos, de certo modo abriu o caminho para o escritor recém-chegado, apresentando-o a editores e tradutores americanos. De sua parte, Brodsky valorizava muito Dovlátov como prosador. No ensaio dedicado à memória do escritor, O Serioje Dovlátove ("Sobre Serioja Dovlátov”, único ensaio do poeta a um prosador contemporâneo), Brodsky estima a poética de Dovlátov:

Antes de tudo, Serioja era um ótimo estilista. Seus contos baseiam-se principalmente no ritmo da frase, na cadência da linguagem do autor. Eles são escritos como poemas: o enredo tem neles um significado secundário, é apenas um pretexto para falar. É mais um canto do que uma narrativa... (Brodsky, 1992, p. 5)

Falando da obra de Serguei Dovlátov, no mesmo artigo, Brodsky levanta a questão do lugar do prosador no contexto da tradição da literatura russa. Para Brodsky, Serguei Dovlátov, em sua obra, não segue a tradição literária russa e tende muito mais à literatura ocidental, principalmente norte-americana. Isso, segundo o poeta, também ajudara no sucesso de Dovlátov entre os leitores americanos (ibid., p. 5). Esse ponto de vista é apoiado também pelos críticos literários Piotr Vail e Aleksandr Guenis, que eram colegas e amigos de Dovlátov. Assim, analisando a poética e o estilo do autor, os dois observam o estilo ocidentalista da prosa de Dovlátov e sua técnica de construção de personagens, mais próxima à literatura norte-americana do que à russa (Vail, 1994). Como outro argumento a favor dessa teoria também é usado o fato de que Serguei Dovlátov sempre admirou e mesmo se considerou influenciado pela obra dos prosadores americanos W. Faulkner e E. Hemingway, muito lidos na União Soviética nos anos 60.

A partir desse ponto de vista sobre os estudos da vida e da obra de Dovlátov, surgiu uma linha que sustenta a ideia de que o autor rompera com a tradição literária russa. Porém, parece-nos que a classificação de Dovlátov como escritor da tradição ocidental tem mais relação com a postura política e as opiniões da geração dos dissidentes em geral do que, de fato, com o estilo do escritor.

Estudos de vários pesquisadores, tanto na Rússia quanto no exterior, conseguiram provar uma relação forte entre Dovlátov e a tradição literária realista russa, com a qual o escritor dialoga, relendo as obras dos maiores clássicos dessa literatura ao longo de toda a sua trajetória literária, o que torna impossível excluí-lo do contexto dessa tradição. Os objetos de reflexão e de criação de Dovlátov são, principalmente, os clássicos como Púchkin, Gógol, Dostoiévski, Tchékhov e outros. A literatura clássica está presente praticamente em todos os livros do escritor. Já no primeiro romance, Zona, escrito nos 
anos 60 , no qual ele relata e recria sua própria experiência de trabalho como guarda de segurança em uma prisão soviética durante seu serviço no exército, o crítico literário Igor Sukhikh vê alusões à obra de Dostoiévski, mais especificamente a Recordações da Casa dos Mortos (Sukhikh, 2006, p. 107).

Podemos chamar de "obra mais literária" de Dovlátov sua novela Zapoviédnik, na qual, partindo de sua experiência como guia no complexo histórico MikháilovskoeTrigórskoe, que funciona atualmente como museu do poeta Aleksandr Púchkin, Dovlátov reflete sobre a tradição literária clássica e os destinos da literatura russa contemporânea. A seguir serão analisados alguns fragmentos dessa novela, no sentido de demonstrar a relação entre a criação do escritor e a tradição literária russa.

\section{Zapoviédnik, de S. Dovlátov: as (re)leituras da tradição literária russa}

A novela Zapoviédnik, escrita por Serguei Dovlátov já na emigração, em 1978, e publicada em 1983, é considerada por alguns estudiosos e leitores a melhor obra do escritor e, por outros, "o livro mais russófobo de Dovlátov" (Popov, 2010, p. 240). Em Zapoviédnik, o herói autobiográfico de Dovlátov, o escritor Borís Alikhánov, narra sua experiência de trabalho como guia no museu-propriedade de Aleksandr Púchkin, o complexo histórico Mikháilovskoe-Trigórskoe. Esse momento, que coincide com a crise familiar (sua mulher e filha estão prestes a emigrar aos Estados Unidos, cumprindo as últimas formalidades) e a crise criativa e existencial na vida do herói, é o momento de escolha entre a emigração e a vida na terra e na cultura natal, porém sob pressão e censura. Podemos considerar essa novela uma das obras mais sombrias e pessimistas de Dovlátov.

Já a primeira publicação chamou a atenção dos críticos, e a obra foi traduzida para vários idiomas, entre eles, o inglês (sob o título The Pushkin Hills), o francês (Le Domaine Pouchkine) e o italiano (Il Parco di Pushkin). A palavra zapoviédnik, em russo, pode referir-se tanto a uma reserva natural quanto a um parque ou propriedade que tenha algum valor histórico ou cultural. Como tradução provisória do título, propomos "Patrimônio", para não limitá-lo ao âmbito da propriedade de Púchkin. Essa tradução parece-nos mais adequada pois, em várias cartas e materiais biográficos, o próprio escritor Serguei Dovlátov dizia que não queria restringir a narrativa ao espaço do complexo histórico Mikháilovskoe-Trigórskoe, mas que ela fosse uma metáfora da vida russa em geral e da “despedida da terra natal” (Dovlátov, Efímov, 2001, p. 259).

Na novela, ao lado de Borís Alikhánov, alter ego de Serguei Dovlátov, está a figura do poeta Aleksandr Púchkin, o segundo personagem principal que aparece em 
várias transformações ao longo da narrativa: tem-se o Púchkin "oficial” do museu, imagem construída pelo regime soviético e totalmente falsa; o Púchkin "verdadeiro", que Alikhánov descobre estudando a vida e a obra do poeta nos acervos do museu; e o Púchkin "espelhado" na figura de Borís Alikhánov, que, aos 30 anos, passa pelas mesmas crises e questiona os mesmos temas que o clássico da literatura russa nessa idade. Além das inúmeras relações amorosas, como Alikhánov, Púchkin tinha problemas com o governo do tzar Nicolau I em razão de suas opiniões políticas, o que o levara a dois exílios, nos quais escreveu algumas de suas melhores obras, abordando os temas do amor, da liberdade, do papel e do destino do escritor.

Além da presença "explícita" da figura do poeta, no texto da novela são abundantes as alusões à sua obra. Assim, a filha de Alikhánov se chama Macha (como a personagem da novela de Púchkin A Filha do Capitão) e sua mulher é Tatiana (a personagem principal do romance em versos Evguéni Oniéguin). A descrição da personagem de Mikhaíl Ivánovitch, morador de uma aldeia próxima ao museu, que aluga um quarto a Alikhánov, remete o leitor ao conto Dubróvski. Referências à obra de Púchkin aparecem também no plano da poética e da linguagem: assim, as descrições da propriedade de Púchkin são feitas em prosa rítmica e pelo texto estão espalhadas várias citações (normalmente corrompidas ou modificadas) da obra do poeta.

A presença de Púchkin, que Dovlátov considerava o exemplo de escritor e o modelo a seguir (o autor trata de sua admiração por Púchkin em vários artigos e palestras), é a mais evidente e presente na novela. No entanto, Dovlátov faz alusões e dialoga com vários escritores clássicos que, para ele, são herdeiros da tradição de Púchkin. Ao longo do texto aparecem referências à obra de Nikolai Gógol (as descrições grotescas da moradia de Mikhaíl Ivánovitch remetem-nos a seu "poema em prosa" Almas mortas), Fiódor Dostoiévski, Liev Tolstói, Evguéni Baratynski, Antón Tchékhov, Serguei Iessiénin e Óssip Mandelstám. Descrevendo o encontro com a futura esposa em Leningrado, Alikhánov, observando a cidade, reflete sobre a tradição realista da São Petersburgo de meados do século XIX, conhecida sob a denominação de "escola natural": "Estava chovendo, e eu pensei: esta é a famosa tradição literária petersburguesa. Toda a decantada 'escola' é uma mera descrição do mau tempo. Todo o 'brilho fosco de seu estilo’ é o asfalto depois da chuva..." (Dovlátov, 2003, p. 226).

A presença dos escritores clássicos na obra é especialmente importante, pois um dos temas principais da novela, ao lado da emigração, é o tema do talento, do ofício de escritor e de seu reconhecimento pelos contemporâneos. Para a personagem de Borís Alikhánov (e também para o próprio Serguei Dovlátov), os grandes representantes da 
literatura clássica russa (e, claro, principalmente Aleksandr Púchkin), os escritores "de fato", se opõem à literatura oficial contemporânea apoiada pelo governo, a qual o escritor vê como falsa, carente de talento, um "quebra-galho" para os autores. Na novela, os escritores contemporâneos são personificados na figura do beletrista Stássik Potótski, um escritor que publica contos sempre parecidos (todos com um final didático) em revistas literárias e é bem visto pelos críticos em razão de sua postura ideológica. Alikhánov descreve a obra de Potótski da seguinte maneira: "Suas narrativas eram triviais, ideologicamente íntegras, primitivas" (ibid., p. 211).

Em nenhum momento Borís Alikhánov põe-se à altura dos clássicos. Ao contrário, ele avalia a si mesmo como um escritor mediano. Porém, diferentemente dos autores contemporâneos reconhecidos pelo poder de promover a ideologia, ele vê na literatura o ofício de sua vida, espaço em que um meio-termo entre o regime e a própria consciência mostra-se impossível.

Outro tema crucial da novela, relacionado tanto com a emigração quanto com o talento e a "literatura de fato", é o destino do escritor no estrangeiro, fora de sua língua materna e de seu contexto cultural. Alikhánov explica à esposa seu medo, sua má vontade de emigrar, dizendo que o escritor está onde estão sua língua materna e seu leitor e que, perdendo-os, no exterior, ele perde tudo: "Mas aqui estão meus leitores. E lá... Quem vai querer meus contos na cidade de Chicago?” (ibid., p. 240). Mas, no fim das contas, o herói vence os medos e, entre a impossibilidade de seguir a vocação na terra natal e a emigração, escolhe a última "para ser um escritor".

A quantidade de alusões à tradição literária clássica, o fato de tomar a postura e usar como principal referência ética e estética um dos escritores mais importantes para o cânone da literatura e, mais amplamente, a cultura russa, Aleksandr Púchkin, junto com os procedimentos poéticos que o autor utiliza, tudo isso nos faz considerar Serguei Dovlátov um escritor que não rompe os laços com a tradição clássica russa, mas que trabalha em sua corrente.

A presença da tradição literária russa se nota ao longo de toda a trajetória literária do autor emigrado. Assim, além da ficção, Dovlátov dedicou alguns artigos e palestras à literatura russa, colocando a si mesmo como seu herdeiro. A presença dessa tradição é perceptível também nos trabalhos mais tardios do escritor, dedicados não à vida na União Soviética, mas na emigração. O próprio Dovlátov, já sendo um sucesso no exterior, sempre falou de si mesmo como um escritor russo.

A relação de integridade entre Serguei Dovlátov e a tradição literária russa pode ser observada no seguinte fragmento de seus cadernos de anotações, publicados pela 
primeira vez em 1990 na coletânea Zapisnye Kníjki ("Cadernos de anotações”), em sua segunda parte, dedicada à vida na emigração, intitulada Solo na IBM ("Um Solo no IBM"):

Cena num hospital. Estão me levando para tratamento. Sobre o meu peito está um tomo da obra de Dostoiévski. Nina Aloviert acaba de trazê-lo para mim. O médico norte-americano me pergunta:

- Que livro é esse?

- Dostoiévski.

- O idiota?

- Não, $O$ adolescente.

- É alguma tradição? - interessa-se o médico.

- Sim - digo -, é uma tradição. Escritores russos morrem com um livro de Dostoiévski sobre peito.

O americano pergunta:

- No Bible? (Não com uma Bíblia?)

- Não - digo -, precisamente com um livro de Dostoiévski.

O americano olhou para mim com interesse. (Dovlátov, 2012, p. 154)

\section{Referências bibliográficas}

Bethea, David M. "Emigration and Heritage". In: The Slavic and East European Journal, vol. 31, Thirtieth Anniversary Issue, 1987, p. 141-164.

Brodsky, Joseph. "O Serioje Dovlátove” (Sobre Serioja Dovlátov). In: Zviezdá. São Petersburgo, $\mathrm{n}^{\mathrm{o}}$ 2, 1992, p. 4-6.

Dovlátov, Serguei. March Odinókikh (A Marcha dos Solitários). Holyoke,

Massachusetts: New England Publishing Co., 1983.

http://www.sergeidovlatov.com/books/marsh.html. . Pissátel v Emigrátsii (O Escritor na Emigração). In: Revista "Slovo-

Word”. Nova York, nº 9, 1991.

http://www.sergeidovlatov.com/books/slovo.html. . Zapoviédnik (Patrimônio). São Petersburgo: Ázbuka, 2003. . Serguei Dovlátov. Vriémia, Miesto, Sudbá (Serguei Dovlátov. Tempo, Lugar, Destino). São Petersburgo: Néstor-Istória, 2006.

Zapisnye Kníjki (Cadernos de Anotações). In: Dovlátov, Serguei.

Uróki Tchtiénia (Lições de Leitura). São Petersburgo: Ázbuka, 2012, p. 39-162. e Efímov, Igor. Epistoliárnyi Roman (Romance Epistolar). Moscou:

Zakhárov, 2001. 
Guenis, Aleksandr. Tchessutchá i Rogoja (Seda e Esteira). In: Dovlátov, Serguei. Rietch bez Póvoda... ili Kolónki Redáktora (Discurso sem Pretexto... ou Colunas do Redator). Moscou: Makhaon, 2006, p. 13-19.

McMillin, Arnold. "Exiled Russian Writers of the Third Wave and the Émigré Press". In: The Modern Language Review. MHRA, vol. 84, nํㅜㄹ, April, 1989, p. 406-413.

Popov, Valiéri. Dovlátov. Moscou: Molodáia Gvárdia, 2010.

Sukhikh, Igor. Serguei Dovlátov. Proza po Kraiám (Serguei Dovlátov. Prosa pelas Bordas). In: Dovlátov, Serguei. Uróki Tchtiénia (Lições de Leitura). São Petersburgo: Ázbuka, 2012, p. 7-36.

Vail, Piotr. Bez Dovlátova (Sem Dovlátov). In: Zviezdá. São Petersburgo, no 3, 1994. http://www.sergeidovlatov.com/books/vail.html. 